\title{
Children's Daily Life after Potentially Traumatic Injury: A Naturalistic Observation
}

Study

\section{Authors:}

Mira Vasileva $^{1 *}$, Elizabeth J. Schilpzand ${ }^{2,3 *}$, Shaminka N. Mangelsdorf ${ }^{2,3,4}$, Rowena Conroy ${ }^{5}$, Anna Barrett ${ }^{2}$, Helen Jowett ${ }^{6}$, Silvia Bressan ${ }^{3,7}$, Franz E. Babl ${ }^{3,6,8}$, Vicki Anderson ${ }^{3,5,6}$, Matthias R. Mehl ${ }^{9}$, Eva Alisic ${ }^{1,2,3}$

* These authors contributed equally to the work.

\section{Affiliations:}

${ }^{1}$ Melbourne School of Population and Global Health, The University of Melbourne, Melbourne, Australia; ${ }^{2}$ Monash University Accident Research Centre, Monash University, Melbourne, Australia; ${ }^{3}$ Murdoch Children’s Research Institute, Melbourne, Australia; ${ }^{4}$ School of Psychological Sciences, Monash University, Melbourne, Australia; ${ }^{5}$ Melbourne School of Psychological Sciences, The University of Melbourne, Melbourne, Australia ${ }^{6}$ The Royal Children's Hospital, Melbourne, Australia; ${ }^{7}$ Department of Woman's and Child’s Health, University of Padova, Padova, Italy; ${ }^{8}$ Department of Paediatrics, The University of Melbourne, Melbourne, Australia; ${ }^{9}$ Department of Psychology, University of Arizona, Tucson, United States of America

(C) 2021, American Psychological Association. This paper is not the copy of record and may not exactly replicate the final, authoritative version of the article. Please do not copy or cite without authors' permission. The final article will be available, upon publication, via its DOI: $10.1037 / \operatorname{trm} 0000301$ 


\section{Correspondence:}

Eva Alisic, Child and Community Wellbeing Unit, Melbourne School of Population and Global Health, University of Melbourne, 207 Bouverie Street, Carlton VIC 3053, Australia. ealisic@unimelb.edu.au

\section{Acknowledgements:}

We would like to thank all the participating families as well as all medical and research staff, and students involved. In particular, we would like to thank Laura Abbey, Naile Alangor, Caitlin Arthur, Hayley Ayton, Caitlin Bishop, Peter Bowles, Prue Dunstan, Shanti Gangatharan, Claire Hoysted, Georgina Johnstone, Maggie Lam, Jasmine Loo, Deborah Lewis, Scott McDonald, Roderick McClure, Cameron Palmer, Julia Polak, Kelly Rentscher, and Claire Wilkin.

This project has been supported by the Netherlands Organisation for Scientific Research (Rubicon Fellowship \#446-11-021); the National Health and Medical Research Council, Australia (Early Career Fellowship \#1090229 and Centre of Research Excellence for Paediatric Emergency Medicine); Monash University (Larkins program); the Australian Government Research Training Program Scholarship; the Victorian Government’s Operational Infrastructure Support Program; and Royal Children’s Hospital Foundation, Melbourne; The German Research Foundation (Research Fellowship \#420503242). 


\begin{abstract}
Objective: Although family environment in the aftermath of potentially traumatic pediatric injury appears critical to recovery, there are no studies observing children's daily life at home. We aimed to explore the daily family environment (activities and interactions) of 3- to 16-year-olds and their families following an injury requiring hospital admission.

Methods: We used the Electronically Activated Recorder (EAR; Mehl et al., 2001) to gather detailed, moment-to-moment observational data for 71 child participants (59\% male; $M$ age $=10.41$ years, $S D=3.60$ ) during two days at home, within a month of their injury. We also explored associations between either acute stress symptoms or perceived social support and characteristics of daily family environment.

Results: Television exposure was a dominant feature in children’s lives, 38.62\% of children's wake time, $S D=22.20 \%$. Children interacted with others an average of $46.80 \%$ of their wake time $(S D=18.05 \%)$. Older children spent more time alone than younger children, and mothers were children's most frequent interaction partners, $44.22 \%$ of children’s interaction time, $S D=22.06 \%$; followed by siblings, $M=36.59 \%$, $S D=28.74 \%$; and fathers, $M=22.78 \%, S D=22.80 \%$. There were few associations between either acute stress symptoms or perceived social support and daily family environment with some correlations varying across child age and sex.
\end{abstract}

Conclusion: The findings give first insights into clinically relevant aspects of child daily family environment after paediatric injury. This study serves as a benchmark for future naturalistic observation studies of family life after trauma.

Keywords: family environment, injury, trauma, social support, children 
Exposure to potentially traumatic events during childhood is prevalent and can result in emotional and behavioral difficulties for both children and their families (McLaughlin et al., 2013). One of the most common childhood experiences of potential psychological trauma is accidental injury (e.g. Elklit \& Frandsen, 2014; Landolt, Schnyder, Maier, Schoenbucher, \& Mohler-Kuo, 2013). Following a child's injury there can be prolonged stress related to the event itself as well as to (the anticipation of) surgical procedures, sometimes lengthy medical treatments, disruption to routines, and physical pain and discomfort (Coyne, 2006).

Numerous studies have shown that children are at risk of developing acute stress and posttraumatic stress symptoms after a pediatric injury that requires hospital admission. For example, one study showed that over $80 \%$ of children experienced at least one clinically significant symptom of acute stress (Winston et al., 2002). A meta-analysis of 22 independent samples indicated that $10 \%$ of children exposed to accidental traumatic events met diagnostic criteria for posttraumatic stress disorder (PTSD; Alisic et al., 2014). However, a metaanalysis by Hiller et al. (2016) also found that most children experience significant spontaneous reductions in both PTSD prevalence and symptom severity in the first six months post-trauma.

Family environment and interactions may be particularly important in facilitating or impeding recovery in the short- to medium-term aftermath of a trauma. In a meta-analysis of the risk factors for the development of PTSD in children and adolescents following potentially traumatic events, Trickey et al. (2012) found that low social support, poor family functioning and social withdrawal showed strong associations with child PTSD symptom severity. Parents are vulnerable to the effects of their children's trauma as well (Lambert, Holzer, \& Hasbun, 2014). They can develop symptoms affecting the way they interact with their children and in turn impacting child post-trauma recovery. In particular, parenting behaviours such as parental overprotection, hostile parenting, and low parental support have 
been linked to child PTSD (Williamson et al., 2017). These findings highlight the importance of considering parent modeling and numerous other aspects of parent-child interactions for recovery in trauma-exposed families (Cobham, McDermott, Haslam, \& Sanders, 2016).

To develop a better understanding of how family environment, including children’s activities and interactions, may influence children’s post-trauma recovery, a clearer understanding is needed of what daily life looks like for children and their families in the aftermath of a serious injury and how these aspects of daily life relate to their psychosocial wellbeing (e.g. their experiences of acute stress and perceived social support). Currently, family environment and interactions at home in the aftermath of trauma take place in a 'black box’ of daily life, from researchers’ perspective. There is no empirical evidence addressing questions such as: Who mostly talks with and supports the child after the event, and how different are families in this regard? How socially engaged or withdrawn is the child in the days and weeks after the event? Capturing the family environment after trauma exposure has been limited by a reliance on questionnaire and interview data, via parent and/or self-report (for overview see Trickey et al., 2012 and Williamson et al., 2017). While valuable, these methods are vulnerable to retrospective bias in reporting. Many less prominent, everyday behaviours that may be relevant to post-trauma recovery are hard to accurately keep track of (for more extensive discussion, see Alisic et al., 2015; Mehl, Robbins, \& große Deters, 2012).

An additional challenge for research investigating trauma, and social development more broadly, is a reliance on mothers (Williamson et al., 2017), due to self-selection or researcher decision. As a consequence, we have little information regarding fathers' role in children’s post-trauma experiences, despite literature suggesting that the mothers, fathers, daughters, and sons discuss emotional experiences differently. For example, mother-child conversations about past emotions have been found to be longer than father-child conversations (Fivush, Brotman, Buckner, \& Goodman, 2000). 
In recognition of these limitations, observational research paradigms are emerging. These include observations in controlled settings (e.g., Marsac \& Kassam-Adams, 2016) as well as naturalistic observations in home settings (e.g., Slatcher \& Trentacosta, 2011). The current study aimed to address the above challenges in the assessment of family environment by using the Electronically Activated Recorder (EAR; Mehl et al., 2001) to gather detailed, moment-to-moment naturalistic observational data on children's daily family environment in the aftermath of a potentially traumatic injury. The EAR captures snippets of acoustic information from participants' daily life, allowing for an observational ecological momentary assessment of participants' experiences and interactions in real time. The snippets are then coded to provide information about the natural social processes occurring in children's family environment. In this way, the EAR preserves aspects of the richness of ethnographic data while, through the coding of the sampled ambient sounds, it enables a quantitative approach to daily-life research. Studying the daily family environment during the short- to mediumterm post-trauma period may provide critical information about why and how some children spontaneously recover yet others develop chronic psychological difficulties. This can inform the development of tailored support.

We aimed to explore the daily family environment of 3- to 16-year-old children following children's exposure to an injury requiring hospital admission. We used the EAR as a naturalistic method to specifically investigate the following questions:

(a) What do children hear (i.e., what are they acoustically exposed to) and do during the day?

(b) What is the nature of children's interactions? In particular, who do they talk with, how often and for how long?

(c) Are there age or sex differences for aspects of children's daily family environment mentioned under (a) or (b)? 
(d) Are aspects of children’s daily family environment mentioned under (a) or (b) associated with children's acute stress symptoms?

(e) Are aspects of children's daily family environment mentioned under (a) or (b) associated with children's perceived social support?

\section{Method}

This study is part of the Ear for Recovery project, a prospective observational study of injured children aged 3- to 16-years and their families, approved by the Human Research Ethics Committee of the Royal Children’s Hospital Melbourne (study number 33103) and the Monash University Human Research Ethics Committee (file number CF13/25152013001322). See Alisic et al. (2015) and Alisic et al. (2017) for a full study protocol and further details.

\section{Participants and Procedure}

Participants were 3- to 16-year-old children who had sustained an injury that resulted in a stay of at least 24 hours at The Royal Children's Hospital (RCH), Australia, and their families. Participants were recruited using inpatient hospital databases. Families were excluded from participating if: (a) the child's injury had been, or was suspected to have been, a result of intentional child maltreatment, child abuse or self-harm; (b) the child arrived at The Royal Children’s Hospital with a Glasgow Coma Scale (Teasdale \& Jennett, 1974) score below 9 (indicating severe head injury), (c) the child's hospital stay exceeded four weeks, or (d) the child's injury was secondary to another medical disorder (since these might not be representative of typical post-injury interactions). Demographic data was retrieved from the medical records. Self-reported data for the current analyses is based on questionnaires that children filled out at their earliest convenience at the hospital or shortly after they returned home. Children were also provided with the EAR to wear at home. Of the 339 families invited to participate in the study, 99 (29\%) consented, consistent with recruitment rates of 
previous pediatric traumatic stress studies focused on family functioning (Coakley et al., 2010; Marsac \& Kassam-Adams, 2016). Of these 99 families, 21 (21\% of invited families) had unusable EAR data (e.g., child did not wear the recording device).

The final sample consisted of 71 child participants (42 males, 29 females; $M$ age $=$ 10.41 years, $S D=3.60$ ). The demographic characteristics of the sample are presented in Table 1. The majority of children were born in Australia (97.2\%) and lived in two-parent families (83.1\%). Caregivers were 69 females and 63 males, who we refer to as mothers and fathers for ease of reading. Children sustained injuries from mild to severe (accordnig to Bolorunduro et al., 2011), predominantly fractures or orthopedic injuries (46.5\%) from sports incidents, falls or traffic crashes.

\section{Measures}

\section{Naturalistic Assessment of Social Processes: Electronically Activated Recorder (EAR)}

We used the iEAR application (Mehl, 2017) on Apple iPod Touch devices that were loaned to the families for children to wear within a flexible belt. Children wore the EAR device during two consecutive days on which they were at home, such as a weekend, public holiday or school holiday, within a month after their injury. The EAR recorded 30 second snippets every five minutes. Our study yielded 19,407 snippets of 30 seconds $(M=273.3$ snippets per family). We asked families to complete a diary to identify their child's activities, who they were with, and any moments when the EAR was not worn by the child. The diary entries indicated that compliance was good: $90.7 \%$ of the snippets were valid.

Once devices were returned to the research team, we transferred the EAR data to a computer, and transcribed and coded each participant's data using two independent coders (the one-way random intraclass correlations indicated adequate inter-coder agreement; ICC > 0.7). A standardised behavioural coding scheme was used, based upon the Social Environment Coding of Sound Inventory (Mehl \& Pennebaker, 2003), a system that details 
acoustically-detectible aspects of participants' social environment and interactions. Each sound file was coded independently by two trained coders with regular supervision. Coding focused on the presence or absence of specific activities (e.g. watching TV, playing), interaction partners (e.g. mother, father and sibling), conversation topics (emotional talk or injury-related talk) or the presence or absence of specific behaviours (e.g. crying, laughing).

\section{Child Acute Stress Reactions}

Children’s acute stress reactions were measured using the Children’s Revised Impact of Event Scale (CRIES-13; Perrin, Meiser-Stedman, \& Smith, 2005). The CRIES-13 measures self-reported intrusion, avoidance, and arousal symptoms with 13 items on a 4point scale. Children who were older than 7 years completed this self-reported questionnaire. Higher scores correspond to more severe symptoms of acute stress. The CRIES-13 showed good reliability $(\alpha=.85)$ and validity in several studies with school-aged children (Alisic \& Kleber, 2010; Perrin et al., 2005). In this sample, internal consistency was $\alpha=.80$. We did not assess self-reported acute stress with children younger than 7 years. Because of their still developing language and cognitive skills, obtaining reliable self-reports from this age-group is difficult (Scheeringa, 2011).

\section{Perceived Social Support (MSPSS)}

Children's perceived social support was measured using the 12-item Multidimensional Scale of Perceived Social Support (MSPSS; Zimet, Dahlem, Zimet, \& Farley, 1988). Children older than 7 years answered on a 7-point scale questions about their perceived support from family members, a special person, and friends. Higher scores indicate more (perceived) social support. The measure has shown good reliability in a previous Australian study with 7- to 17-year-old children and adolescents $(\alpha=.90$; Ellis, Nixon, \& Williamson, 2009). There was good reliability in the current sample as well ( $\alpha=.90)$.

\section{Statistical Analyses}


We used descriptive statistics to explore children's daily family environment (research question (a)), presenting them as a percentage of children’s time awake (for activities, interaction characteristics, and emotion expression) or as percentage of their interactions (for interaction partners and nature of interaction). We translated percentages of children's time awake to the equivalent of absolute time during which a child is typically awake in a day (i.e. approx.15 hours; Olds, Maher, \& Matricciani, 2011). To investigate research question (b), we conducted ANOVAs to compare across age groups (3-7 years old, 8-12 years old, 13-16 years old) and sex (boy, girl). Standard errors for these comparisons were based on 1000 bootstrap samples. For post-hoc age group comparisons we used Scheffe's correction of Alpha inflation. Furthermore, we calculated point (Spearman's $\rho$ ) and interval estimates (95\% confidence intervals) of the association between characteristics of daily family environment and child acute stress symptoms as well as social support for children older than 7 years. Correlations were differentiated across child’s age and sex (research question (c) and (d)). We selected Spearman's correlation coefficient because there was a positive skew in most EAR variables and Spearman's correlations tend to be more robust than Pearson’s correlations to violations of normality (de Winter, Gosling, \& Potter, 2016). We used $p<.05$ as threshold for statistical significance. Since this was an exploratory analysis, we tolerated the risk of $5 \%$ for false positive results or an overestimation of effects due to the relatively small sample size. Our goal was to inform future studies about potential important dimensions from the vast majority of characteristics of daily family environment.

\section{Results}

\section{What do children hear and do during the day?}

Television was a dominant feature in children's environment (on average 38.62\% of children's wake time, $S D=22.20 \%$, range 0\%-90.36\%). Television use did not differ significantly across age groups or between boys and girls (Table 2). Child play decreased 
with age. Boys were more likely than girls to be engaged in gaming activities. Children aged between 8 and 12 years listened to the radio/music more, $F_{2,65}=3.43, p=.038, \eta^{2}=.10$, and played more games than the younger and older age-groups, $F_{2,65}=3.28, p=.044, \eta^{2}=.09$.

\section{What is the nature of children's interactions?}

Children interacted with others during nearly half of the time that they spent awake $(46.80 \%, S D=18.05 \%)$, corresponding to, on average, 7.0 hours in a 15 -hour day. There was substantial variation; the proportion of time spent in interactions ranged from $6.11 \%$ to 82.76\%, corresponding to 0.9 and 12.4 hours in a typical day. Children interacted most with their mothers ( $M=44.22 \%$ of children's interaction time, $S D=22.06 \%$, range: $0 \%-92.5 \%$ ), followed by siblings $(M=36.59 \%, S D=28.74 \%$, range: $0 \%-91.40 \%)$ and fathers $(M=$ $22.78 \%, S D=22.80 \%$, range: $0 \%$ - 90.91\%). Children spent $10.96 \%$ of their wake-time (SD $=13.21$, range: $0 \%-64.71 \%)$ talking about the injury and $10.82 \%(S D=6.94$, range: $0 \%$ 35.14\%) in conversations in which one of the interaction partners shared their emotions.

There were several differences across age groups and sex (Table 2). Older children between 13 and 16 years talked less in general, $F_{2,65}=8.50, p=.001, \eta^{2}=.21$, but proportionally more about the injury, $F_{2,65}=4.17, p=.020, \eta^{2}=.11$, compared to younger children. With each older age group, children spent more time alone, $F_{2,65}=13.64, p<.001$, $\eta^{2}=.30$. Younger children (3- to 7-years old) interacted more with their siblings than $13-$ to 16-year-olds, $F_{2,65}=3.50, p=.036, \eta^{2}=.10$. They also cried and sang more than 8 - to 12 year-old and 13- to 16-year-old children (crying: $F_{2,65}=12.60, p<.001, \eta^{2}=.28$, singing: $F_{2}$, $\left.65=5.18, p=.008, \eta^{2}=.14\right)$.

While girls interacted more with their mothers than boys, $F_{1,65}=4.92, p=.030, \eta^{2}=$ .07 , boys interacted more with their fathers, $F_{1,65}=35.82, p=.019, \eta^{2}=.08$. Girls also spent more time crying, $F_{1,65}=4.31, p=.042, \eta^{2}=.06$. There were no significant differences 
between boys and girls in how much time they talked, spent alone, or talked about the injury or about emotions.

The analysis of variance showed significant interaction for age and sex on playing, $F_{2}$, $65=4.29, p=.018, \eta^{2}=.12$, such that younger boys (3-7 years old) spent more time playing than girls, while there were no differences for older children.

\section{Association between daily family environment, acute stress and perceived social support}

Using self-report data assessed with children older than 7 years, we examined whether children’s acute stress symptoms and perceived social support were associated with characteristics of the daily family environment. In the full sample, higher levels of acute stress symptoms were associated with a higher amount of time spent crying, $r=.28, d f=48$, $p=.048$. Child social support correlated positively with child play, $r=.33, d f=48, p=.021$.

There were some differences between age groups and between boys and girls (Figures 1 and 2). There was a significant positive association between acute stress symptoms and time spent crying for 8- to 12-year-old, but not 13- to 16-year-old, children, $r=.45, d f=25$, $p=.019$. For 8- to 12-year-old boys, more severe acute stress symptoms were associated with more time exposed to TV sounds, $r=.52, d f=13, p=.047$. For 13 - to 16 -year-old participants and especially for girls, acute stress symptoms correlated negatively with gaming (all 13- to 16-year-old participants: $r=-.44, d f=19, p=.048$; 13 - to 16-year-old girls: $r=$ $.74, d f=6, p=.037)$. Acute stress symptoms in 13- to 16 -year-old girls were also associated with more time spent alone, $r=.85, d f=6, p=.007$.

There was significant association between lower perceived social support and TV exposure for 13- to 16-year old girls, $r=-.78, d f=16, p=.023$. For older children and adolescents, especially girls, and boys in general, more perceived social support correlated with more time spent playing (all 13-to 16-year-old participants: $r=.44, d f=19, p=.045$; 13- to 16-year-old girls: $r=.753, d f=6, p=.031$; boys: $r=.45, d f=27, p=.014$ ). In girls, 
particularly 8- to 12 year old girls more perceived social support correlated with more interaction with fathers (girls: $r=.48, d f=19, p=.003$; 8 - to 12-year old girls: $r=.74, d f=$ $10, p<.001$ ) but also with less time spent gaming (girls: $r=-.45, d f=19, p=.042$, 8- to $12-$ year-old girls: $-.63, d f=10, p=.028$ ). For boys in general and particularly 8 - to 12 -year-old boys, there was a significant positive relationship between perceived social support and more time spent crying (boys: $r=.45, d f=27, p=.014$; 8- to 12-year-old boys: $r=.56, d f=12$, $p=.030)$.

\section{Discussion}

The current study provides rich and novel data on children's family life after a potentially traumatic event. The naturalistic observations captured some data that may represent direct indicators of injury outcomes, for example, acute stress symptoms were associated with more time crying. We found very few differences in daily family environment across age groups and sex. There were few associations between acute stress symptoms or perceived social support and daily family environment varying across age (e.g. gaming was associated with less acute stress symptoms in older children) and sex (e.g. more interactions with the father were associated with more perceived social support only for girls). Although we tolerated a relatively high risk for false positive inferences, the findings contribute directly to our knowledge of children's daily family environment and interactions in the aftermath of injury. They serve as a benchmark for future studies among groups with similar or different trauma exposure and demographic characteristics.

Diversity in daily lives after a serious injury was a key finding in this study. Child interaction with others varied between $7 \%$ and $82 \%$ of their time awake; variation was also reflected in the high standard deviations of some interaction characteristics, for example, injury talk. Some of these variations could be explained by developmental characteristics, with young children interacting more with other family members than older children, and 
older children talking more about the injury than younger children. Interaction with parents has a major emotion regulation function for younger children (Lincoln, Russell, Donohue, \& Racine, 2017), while for older children and adolescents the importance of family interactions and support decrease with age (Furman \& Buhrmester, 1992). However, for most characteristics of daily family environment no differences were found across age groups and sex. Our relatively small sample limited the statistical power to detect small effects. The great variation in the nature of family interactions justifies analytical methods that allow for, and track, individual differences. For instance, in-depth qualitative analysis of four cases of the current data showed that an individual-centered approach to EAR data analysis can enhance clinically relevant interpretations (Mangelsdorf, Conroy, Mehl, Norton, \& Alisic, 2019).

Despite the diversity, the television emerged as a dominant feature in children's lives (during 38\% of child activities); only few children did not have substantial proportion of television sounds in their wake-time and children spent on average 5.8 hours exposed to TV sounds. Per protocol children wore the EAR recording devices on two days that they spent mostly at home (e.g. weekends or holidays), so findings cannot be generalised to weekdays. We also could not differentiate if children were watching TV or if they were doing something else while the TV was on (which might differ across age groups). This exposure to TV sounds was higher than in a previous EAR study of children (Slatcher \& Trentacosta, 2011) and in the general Australian population (average 2 hours television viewing; Australian Communications and Media Authority, 2015). We also received qualitative feedback from families that they did indeed use television and games as a distraction or time filler, especially for children who were limited in their mobility because of the injury. Our results showed positive association between acute stress symptoms and TV exposure for 8- to 12year-old boys and 13- to 16-year-old girls. Previous studies have shown inconsistent results about the effect of TV on children's mental health. It seems that specific contents (e.g. 
violence) or sedentary behaviour associated with TV viewing might have a negative effect on child well-being rather than the duration of TV exposure (de Wit, van Straten, Lamers, Cuijpers, \& Penninx, 2011; McVeigh, Smith, Howie, \& Straker, 2016). Time spent watching TV might indicate time not interacting with the parents. However, since the association found in our study was strongly age- and sex-specific, we have no sufficient support for a negative effect of TV exposure. Television or other electronic media could even be considered as potential media to support children within certain age-groups post-trauma.

The current results showed that mothers were the predominant interaction partners for the children in this study, followed by siblings. Our findings about siblings as another main interaction partner besides mothers suggest considering siblings as an important potential resource for trauma recovery (Rustin, 2007). Furthermore, siblings might suffer from posttraumatic stress symptoms if they were exposed to the same accident, which might impact on sibling recovery.

Our study also showed that more interactions with the father correlated with more perceived social support, especially for girls. Father involvement has long-term influence on children’s mental health (Flouri \& Buchanan, 2003). Hence, our findings of the low involvement of fathers compared to mothers suggest that children might be missing an important source of social support from their fathers. This could be incorporated into clinical interventions involving fathers more intensively in the early post-trauma period.

There were only few correlations between interaction characteristics and either acute stress symptoms or social support. It is possible that children's acute stress symptoms and perceived social support are associated with internal rather than social processes. For example, a recent study found that the use of emotion-related words in interactions did not reflect self-reported emotional state suggesting that there are stronger indirect pathways between internal emotional states and social processes (Sun, Schwartz, Son, Kern, \& Vazire, 
2019). Children in the current sample showed in general low levels of acute stress symptoms and EAR data has better discriminating power with high levels of psychopathology (Mehl, 2006). Furthermore, there are aspects of the quality of interactions that EAR cannot capture (e.g. proximity in nonverbal communication) which might be reflected in the absence of associations with acute stress symptoms and perceived social support. We also investigated the association between characteristics of interactions and psychological variables of one of the interaction partners, i.e. the child. The quality and quantity of interactions depend on the cognitive and emotional states of all interaction partners. Slatcher and Trentacosta (2011) showed in their study of preschool children that parents' mental health has an impact on children's daily family environment assessed by the EAR. It is also possible that some parents who were aware of the acute stress reaction of their children spent more time interacting with them. Hence, it is important to combine observational with self-reported data of several family members in order to better understand the association between internal processes (e.g. emotional state, motivation) and family interaction.

There were some age and sex differences in the association between daily family environment and acute stress symptoms or perceived social support. For example, gaming was associated with fewer acute stress symptoms in 13- to 16-year-old children but was also correlated with less perceived social support in girls in general and in 13-16-year-olds. It is possible that older children and adolescents used gaming as an avoidant coping strategy that reduces symptoms short term but is associated with maintenance of posttraumatic stress symptoms long-term (Pineles et al., 2011). Gaming behaviour in girls with low perceived social support might be related to their tendency to internalize symptoms and to seek for solace in a cyber world (Rikkers, Lawrence, Hafekost, \& Zubrick, 2016). Future studies are needed to measure if gaming behaviour differed pre and post trauma. 
There are some limitations of the current study. First, the ecological validity of the type of data collected comes with a notable trade-off of having a relatively small sample size with limited statistical power. Our findings should be considered entirely exploratory and need to be confirmed in larger studies with a priori hypotheses. Second, although our recruitment rate is in line with previous studies (e.g., Marsac \& Kassam-Adams, 2016), the sample represents only a portion of all families who have a child admitted to hospital after sustaining a serious injury. Hence, there might be a selection bias. We also included only families who spoke English. Finally, the current data are virtually cross-sectional (there was a small time-lag between the questionnaires and the subsequent EAR recording, but we do not consider this sufficiently long), and as such do not allow for any causal inferences regarding associations between children's social processes and their acute stress or perceived social support. We have not assessed if daily family environment changed after the incident and could not compare the data with a normative sample of children without injury exposure.

This study, including its methodology, generates multiple new avenues for child trauma research focused on understanding the daily family environment. It shows that it is possible to capture aspects of the daily family environment and interactions in the family in real-time. Future studies may focus on finding further clinically relevant factors that can explain the great variability in daily family environments. The study provides a benchmark for future research. Since this is the first study to explore, in real-time, family environment in the aftermath of potentially traumatic experiences, it would be very interesting to see whether results can be replicated with other samples (e.g. in other hospitals, other countries, following other types of trauma). It would be of interest to have a large study that tracks social processes starting in-hospital and moving through time until post-injury. Our study is just a first step in a longer process of research, and we hope that the current data provide a useful building block in research on social processes after a child's exposure to trauma. 


\section{References}

Alisic, E., Barrett, A., Bowles, P., Babl, F. E., Conroy, R., McClure, R. J., et al. (2015). Ear for recovery: Protocol for a prospective study on parent-child communication and psychological recovery after paediatric injury. BMJ open, 5, e007393. doi:10.1136/bmjopen-2014-007393

Alisic, E., Gunaratnam, S., Barrett, A., Conroy, R., Jowett, H., Bressan, S., et al. (2017). Injury talk: Spontaneous parent-child conversations in the aftermath of a potentially traumatic event. Evidence-based Mental Health, 20, e19-e20. doi:10.1136/eb-2017102736

Alisic, E., \& Kleber, R. J. (2010). Measuring Posttraumatic stress reactions in children: A preliminary validation of the children's responses to trauma inventory. Journal of Child \& Adolescent Trauma, 3, 192-204. doi:10.1080/19361521.2010.500979

Alisic, E., Zalta, A. K., Wesel, F. V., Larsen, S. E., Hafstad, G. S., Hassanpour, K., et al. (2014). Rates of post-traumatic stress disorder in trauma-exposed children and adolescents: Meta-analysis. The British Journal of Psychiatry, 204, 335-340. doi:10.1192/bjp.bp.113.131227

Australian Communications and Media Authority. (2015). Children's television viewing. Research overview. In: Australian Communications and Media Authority.

Bolorunduro, O. B., Villegas, C., Oyetunji, T. A., Haut, E. R., Stevens, K. A., Chang, D. C., et al. (2011). Validating the Injury Severity Score (ISS) in different populations: ISS predicts mortality better among Hispanics and females. Journal of Surgical Research, 166, 40-44. doi:10.1016/j.jss.2010.04.012

Coakley, R. M., Forbes, P. W., Kelley, S. D., LeBovidge, J., Beasley, P., DeMaso, D. R., et al. (2010). Family functioning and posttraumatic stress symptoms in youth and their 
parents after unintentional pediatric injury. Journal of Traumatic Stress, 23, 807-810. doi:10.1002/jts.20586

Cobham, V. E., McDermott, B., Haslam, D., \& Sanders, M. R. (2016). The role of parents, parenting and the family environment in children's post-disaster mental health. Current Psychiatry Reports 18, 1-9. doi:10.1007/s11920-016-0691-4

Coyne, I. (2006). Children's experiences of hospitalization. Journal of Child Health Care, 10, 326-336. doi:10.1177/1367493506067884

de Winter, J. C., Gosling, S. D., \& Potter, J. (2016). Comparing the Pearson and Spearman correlation coefficients across distributions and sample sizes: A tutorial using simulations and empirical data. Psychological Methods, 21, 273-290. doi:10.1037/met0000079

de Wit, L., van Straten, A., Lamers, F., Cuijpers, P., \& Penninx, B. (2011). Are sedentary television watching and computer use behaviors associated with anxiety and depressive disorders? Psychiatry Research, 186, 239-243. doi:10.1016/j.psychres.2010.07.003

Elklit, A., \& Frandsen, L. (2014). Trauma exposure and posttraumatic stress among Danish adolescents. Journal of Traumatic Stress Disorders \& Treatment, 3. doi:10.4172/2324-8947.1000135

Ellis, A. A., Nixon, R. D., \& Williamson, P. (2009). The effects of social support and negative appraisals on acute stress symptoms and depression in children and adolescents. British Journal of Clinical Psychology, 48, 347-361. doi:10.1348/014466508X401894

Fivush, R., Brotman, M. A., Buckner, J. P., \& Goodman, S. H. (2000). Gender differences in parent-child emotion narratives. Sex Roles, 42, 233-253. doi:10.1023/A:1007091207068 
Flouri, E., \& Buchanan, A. (2003). The role of father involvement in children's later mental health. Journal of Adolescence, 26, 63-78. doi:10.1016/S0140-1971(02)00116-1

Furman, W., \& Buhrmester, D. (1992). Age and sex differences in perceptions of networks of personal relationships. Child Development, 63, 103-115. doi:10.1111/j.14678624.1992.tb03599.x

Hiller, R. M., Meiser - Stedman, R., Fearon, P., Lobo, S., McKinnon, A., Fraser, A., et al. (2016). Research Review: Changes in the prevalence and symptom severity of child post - traumatic stress disorder in the year following trauma - a meta - analytic study. Journal of Child Psychology and Psychiatry, 57, 884-898. doi:10.1111/jcpp.12566

Lambert, J. E., Holzer, J., \& Hasbun, A. (2014). Association between parents’ PTSD severity and children's psychological distress: A meta-analysis. Journal of Traumatic Stress, 27, 9-17. doi:10.1002/jts.21891

Landolt, M. A., Schnyder, U., Maier, T., Schoenbucher, V., \& Mohler-Kuo, M. (2013). Trauma exposure and posttraumatic stress disorder in adolescents: A national survey in Switzerland. Journal of Traumatic Stress, 26, 209-216. doi:10.1002/jts.21794

Lincoln, C. R., Russell, B. S., Donohue, E. B., \& Racine, L. E. (2017). Mother-child interactions and preschoolers’ emotion regulation outcomes: Nurturing autonomous emotion regulation. Journal of Child Family Studies, 26, 559-573. doi:10.1007/s10826-016-0561-z

Mangelsdorf, S. N., Conroy, R., Mehl, M. R., Norton, P. J., \& Alisic, E. (2019). Listening to family life after serious pediatric injury: A study of four cases. Family Process. doi:10.1111/famp.12490

Marsac, M. L., \& Kassam-Adams, N. (2016). A novel adaptation of a parent-child observational assessment tool for appraisals and coping in children exposed to acute 
trauma. European Journal of Psychotraumatology, 7, 31879.

doi:10.3402/ejpt.v7.31879

McLaughlin, K. A., Koenen, K. C., Hill, E. D., Petukhova, M., Sampson, N. A., Zaslavsky, A. M., et al. (2013). Trauma exposure and posttraumatic stress disorder in a national sample of adolescents. Journal of the American Academy of Child and Adolescent Psychiatry, 52, 815-830. e814. doi:10.1016/j.jaac.2013.05.011

McVeigh, J., Smith, A., Howie, E., \& Straker, L. (2016). Trajectories of television watching from childhood to early adulthood and their association with body composition and mental health outcomes in young adults. PLoS One, 11, e0152879. doi:10.1371/journal.pone.0152879

Mehl, M. R. (2006). The lay assessment of subclinical depression in daily life. Psychological Assessment, 18, 340-345. doi:10.1037/1040-3590.18.3.340

Mehl, M. R. (2017). The Electronically Activated Recorder (EAR) A Method for the Naturalistic Observation of Daily Social Behavior. Current Directions in Psychological Science, 26, 184-190. doi:10.1177/0963721416680611

Mehl, M. R., \& Pennebaker, J. W. (2003). The sounds of social life: a psychometric analysis of students' daily social environments and natural conversations. Journal of Personality and Social Psychology, 84, 857-870. doi:10.1037/0022-3514.84.4.857

Mehl, M. R., Pennebaker, J. W., Crow, D. M., Dabbs, J., \& Price, J. H. (2001). The Electronically Activated Recorder (EAR): A device for sampling naturalistic daily activities and conversations. Behavior Research Methods, 33, 517-523. doi:10.3758/BF03195410

Mehl, M. R., Robbins, M. L., \& große Deters, F. (2012). Naturalistic observation of healthrelevant social processes: The Electronically Activated Recorder (EAR) methodology 
in psychosomatics. Psychosomatic Medicine, 74, 410-417. doi:10.1097/PSY.0b013e3182545470

Olds, T. S., Maher, C. A., \& Matricciani, L. (2011). Sleep duration or bedtime? Exploring the relationship between sleep habits and weight status and activity patterns. Sleep, 34, 1299-1307. doi:10.5665/SLEEP.1266

Perrin, S., Meiser-Stedman, R., \& Smith, P. (2005). The Children's Revised Impact of Event Scale (CRIES): Validity as a screening instrument for PTSD. Behavioural and Cognitive Psychotherapy, 33, 487-498. doi:10.1017/S1352465805002419

Pineles, S. L., Mostoufi, S. M., Ready, C. B., Street, A. E., Griffin, M. G., \& Resick, P. A. (2011). Trauma reactivity, avoidant coping, and PTSD symptoms: A moderating relationship? Journal of Abnormal Psychology, 120, 240-246. doi:10.1037/a0022123

Rikkers, W., Lawrence, D., Hafekost, J., \& Zubrick, S. R. (2016). Internet use and electronic gaming by children and adolescents with emotional and behavioural problems in Australia-results from the second Child and Adolescent Survey of Mental Health and Wellbeing. BMC Public Health, 16, 399. doi:10.1186/s12889-016-3058-1

Rustin, M. (2007). Taking account of siblings-a view from child psychotherapy. Journal of Child Psychotherapy, 33, 21-35. doi:10.1080/00754170701195637

Scheeringa, M. S. (2011). PTSD in children younger than the age of 13: Toward developmentally sensitive assessment and management. Journal of Child \& Adolescent Trauma, 4, 181-197. doi:10.1080/19361521.2011.597079

Slatcher, R. B., \& Trentacosta, C. (2011). A naturalistic observation study of the links between parental depressive symptoms and preschoolers' behaviors in everyday life. Journal of Family Psychology, 25, 444-448. doi:10.1037/a0023728 
Sun, J., Schwartz, H. A., Son, Y., Kern, M. L., \& Vazire, S. (2019). The language of wellbeing: Tracking fluctuations in emotion experience through everyday speech. Journal of Personality and Social Psychology. doi:10.1037/pspp0000244

Teasdale, G., \& Jennett, B. (1974). Assessment of coma and impaired consciousness: a practical scale. The Lancet, 304, 81-84. doi:10.1016/S0140-6736(74)91639-0

Trickey, D., Siddaway, A. P., Meiser-Stedman, R., Serpell, L., \& Field, A. P. (2012). A metaanalysis of risk factors for post-traumatic stress disorder in children and adolescents. Clinical Psychology Review, 32, 122-138. doi:10.1016/j.cpr.2011.12.001

Williamson, V., Creswell, C., Fearon, P., Hiller, R. M., Walker, J., \& Halligan, S. L. (2017). The role of parenting behaviors in childhood post-traumatic stress disorder: A metaanalytic review. Clinical Psychology Review, 53, 1-13. doi:10.1016/j.cpr.2017.01.005

Winston, F. K., Kassam-Adams, N., Vivarelli-O’Neill, C., Ford, J., Newman, E., Baxt, C., et al. (2002). Acute stress disorder symptoms in children and their parents after pediatric traffic injury. Pediatrics, 109, e90-e90. doi:10.1542/peds.109.6.e90

Zimet, G. D., Dahlem, N. W., Zimet, S. G., \& Farley, G. K. (1988). The multidimensional scale of perceived social support. Journal of Personality Assessment, 52, 30-41. doi:10.1207/s15327752jpa5201_2 
Table 1

Sample Characteristics $(N=71)$

Demographic Characteristics

Range

M

$S D$

$N \quad \%$

\section{Child Characteristics}

Child age at EAR recording

$$
\text { 3-16 }
$$

10.41

3.60

(years)

Child age group

3-7 years old

8-12 years old

13-16 years old

Child sex

Male

Female

Child born in Australia

\section{Family Characteristics}

Parents living with child

Both parents present

Mother only

Father only

Social advantage (SEIFA) ${ }^{\mathrm{a}}$

\section{Injury Characteristics}

Injury Mechanism

Motor vehicle accident

Fall

Sports and recreation

Other circumstances

Injury Type

Fracture/orthopedic

Soft tissue injuries

Head injury

Multiple trauma

Other

88.47-1117.40

$\begin{array}{llll}- & - & 18 & 25.4 \\ - & - & 30 & 42.3 \\ - & - & 23 & 32.4\end{array}$

$\begin{array}{lll}- & - & 42\end{array}$

59.2

$\begin{array}{ll}- & 29 \\ - & 40.8\end{array}$

$\begin{array}{lll}- & - & 69\end{array}$

Injury Severity (ISS08)
Total days in hospital

$\begin{array}{ccccc}- & - & - & 61 & 85.9 \\ - & - & - & 8 & 11.3 \\ - & - & - & 2 & 2.8 \\ 88.47-1117.40 & 1013.60 & 54.65 & - & -\end{array}$


Table 2

Mean Comparison of Children's Daily Family Environment by Age Group and Sex

\begin{tabular}{|c|c|c|c|c|c|c|c|c|}
\hline \multirow[t]{2}{*}{ Daily Family Environment } & \multicolumn{2}{|c|}{ 3-7 years old, } & \multicolumn{2}{|c|}{ 8-12 years old } & \multicolumn{2}{|c|}{ 13-16 years old } & \multirow{2}{*}{$\begin{array}{l}\text { Total } \\
N=71\end{array}$} & \multirow[t]{2}{*}{ ANOVA } \\
\hline & $\begin{array}{c}\text { Boys } \\
n=12\end{array}$ & $\begin{array}{l}\text { Girls } \\
n=6\end{array}$ & $\begin{array}{c}\text { Boys } \\
n=17\end{array}$ & $\begin{array}{c}\text { Girls } \\
n=13\end{array}$ & $\begin{array}{c}\text { Boys } \\
n=13\end{array}$ & $\begin{array}{c}\text { Girls } \\
n=10\end{array}$ & & \\
\hline \multicolumn{9}{|l|}{ Activities $^{a}$} \\
\hline Radio/music on & $3.4(2.4)$ & 5.7 (3.6) & $11.4(10.1)$ & 10.5 (13.0) & 3.9 (3.7) & $9.4(8.8)$ & $7.8(8.8)$ & A \\
\hline TV on & $36.3(19.0)$ & $43.2(19.9)$ & $32.3(18.6)$ & $35.4(26.7)$ & $37.4(21.7)$ & $55.4(23.6)$ & $38.6(22.2)$ & \\
\hline Child gaming & $8.1(10.5)$ & $4.2(5.3)$ & $23.4(17.3)$ & $4.7(8.0)$ & $12.7(13.7)$ & $1.1(2.1)$ & $10.7(14.0)$ & S, A \\
\hline Child playing & $18.1(13.5)$ & $6.2(7.1)$ & $3.8(6.6)$ & $3.4(4.5)$ & $0.4(0.9)$ & $0.5(1.6)$ & $5.3(9.1)$ & $\mathrm{S}, \mathrm{A}, \mathrm{S}^{*} \mathrm{~A}$ \\
\hline \multicolumn{9}{|l|}{ Interaction characteristics ${ }^{\text {a }}$} \\
\hline Child talks & $61.4(13.0)$ & $52.6(14.7)$ & $50.6(12.9)$ & $45.6(19.1)$ & $33.8(19.5)$ & $37.9(15.9)$ & $46.8(18.1)$ & A \\
\hline Child alone & $14.2(7.3)$ & $20.5(14.5)$ & 27.5 (15.9) & $34.6(22.5)$ & $51.2(21.3)$ & $43.1(19.1)$ & $32.5(21.2)$ & A \\
\hline \multicolumn{9}{|l|}{ Interaction partners ${ }^{b}$} \\
\hline Mother & $45.9(20.2)$ & $62.7(19.7)$ & $32.2(11.9)$ & $46.8(26.4)$ & $46.3(25.8)$ & $45.3(21.9)$ & $44.2(22.1)$ & \\
\hline Father & 34.8 (18.3) & $13.5(14.1)$ & 23.7 (26.3) & $23.2(30.0)$ & $20.3(20.4)$ & $15.2(14.5)$ & $22.8(22.8)$ & \\
\hline Sibling & $52.2(28.9)$ & $39.9(32.1)$ & $43.2(29.9)$ & $34.8(29.2)$ & $40.1(29.5)$ & $22.0(21.1)$ & $36.6(28.7)$ & $\mathrm{A}$ \\
\hline \multicolumn{9}{|l|}{ Nature of interaction ${ }^{b}$} \\
\hline Emotion talk & $9.5(5.6)$ & $7.8(2.8)$ & $7.8(3.6)$ & $14.0(8.0)$ & $11.58(9.0)$ & $14.3(7.9)$ & $10.8(6.9)$ & \\
\hline Injury talk & $12.1(16.9)$ & $5.0(2.6)$ & $5.1(4.6)$ & $9.1(8.2)$ & $21.5(19.2)$ & $11.9(11.5)$ & $11.0(12.2)$ & A \\
\hline \multicolumn{9}{|l|}{ Emotional expression $^{a}$} \\
\hline Laughing & $5.8(4.5)$ & $3.8(1.5)$ & $4.7(3.1)$ & $6.5(5.6)$ & $4.6(4.3)$ & $6.7(5.7)$ & $5.4(4.4)$ & \\
\hline Crying & $0.8(1.0)$ & $1.9(2.2)$ & $0.1(0.2)$ & $0.3(0.6)$ & $0.2(0.5)$ & $0.1(0.3)$ & $0.4(1.0)$ & S, A \\
\hline Singing & $4.4(3.6)$ & $4.7(4.0)$ & $3.2(3.5)$ & $5.6(6.2)$ & $0.5(0.7)$ & $2.1(2.0)$ & $3.3(4.0)$ & A \\
\hline
\end{tabular}

Note. ${ }^{a} \%$ of wake time, mean (SD) ${ }^{b} \%$ of interactions (SD), A = Main effect of Age, $\mathrm{S}=$ Main effect of Sex, G*A = Age by Sex interaction 


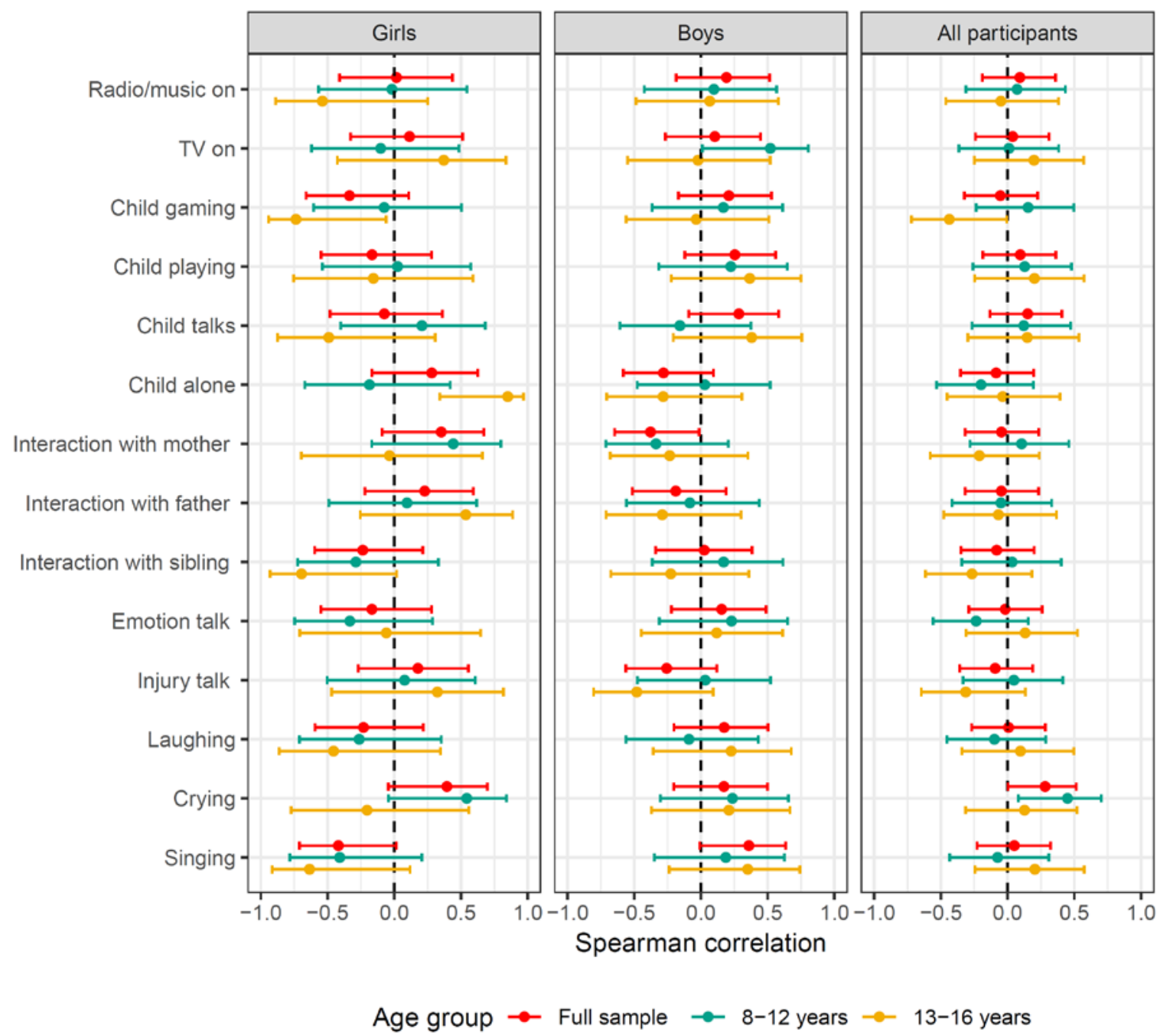

Figure 1. Correlations between acute stress symptoms and daily family environment and 95\% confidence intervals 


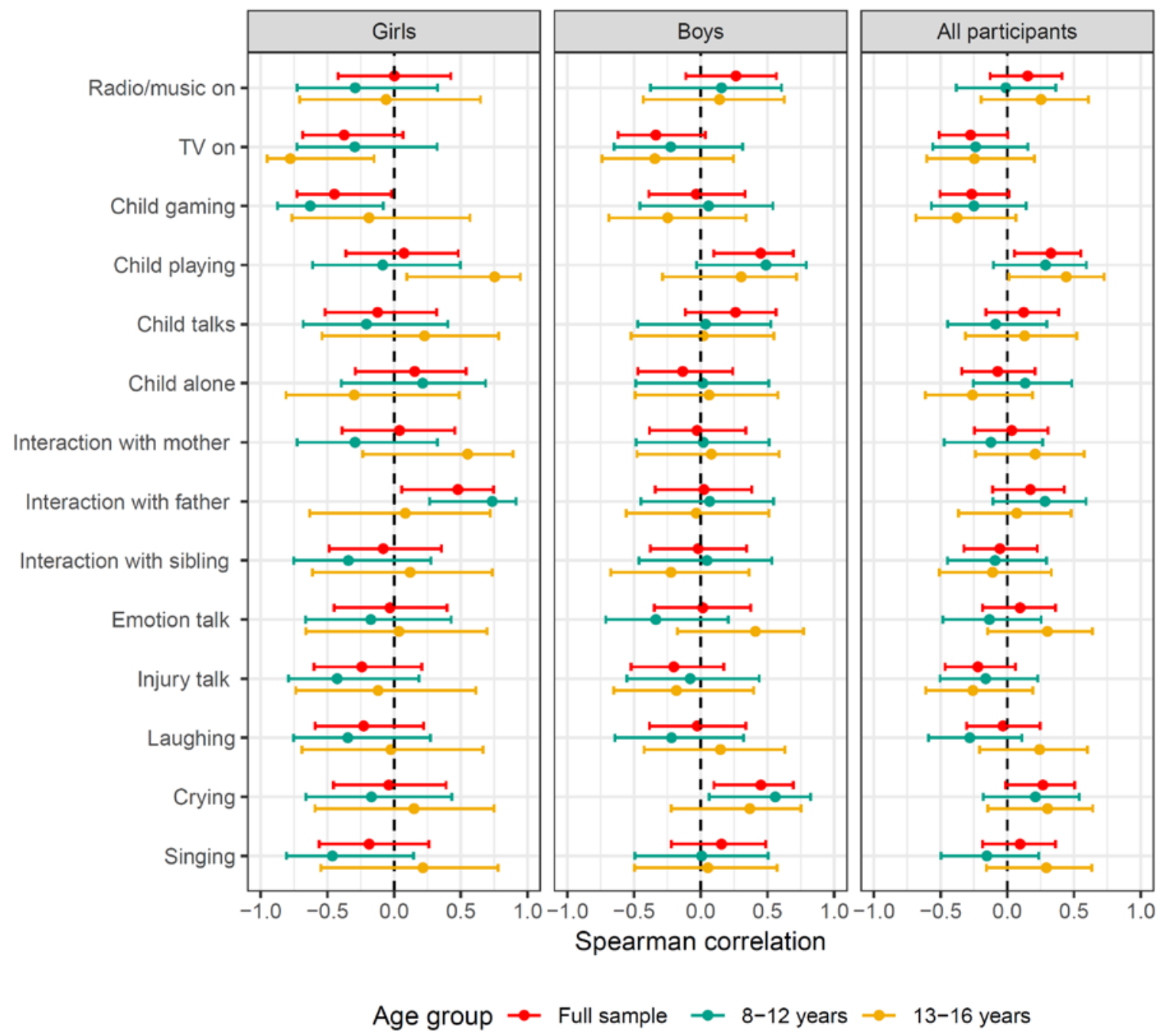

Figure 2. Correlations between perceived social support and daily family environment and 95\% confidence intervals 


\section{University Library}

\section{- M M N E R VA A gateway to Melbourne's research publications}

Minerva Access is the Institutional Repository of The University of Melbourne

\section{Author/s:}

Vasileva, M;Schilpzand, EJ;Mangelsdorf, SN;Conroy, R;Barrett, A;Jowett, H;Bressan, S;Babl, FE;Anderson, V;Mehl, MR;Alisic, E

Title:

Children's Daily Life After Potentially Traumatic Injury: A Naturalistic Observation Study

Date:

2022-03-01

\section{Citation:}

Vasileva, M., Schilpzand, E. J., Mangelsdorf, S. N., Conroy, R., Barrett, A., Jowett, H., Bressan, S., Babl, F. E., Anderson, V., Mehl, M. R. \& Alisic, E. (2022). Children's Daily Life After Potentially Traumatic Injury: A Naturalistic Observation Study. TRAUMATOLOGY, 28 (1), pp.129-137. https://doi.org/10.1037/trm0000301.

Persistent Link:

http://hdl.handle.net/11343/274922 